Bond University

Research Repository

\title{
Informational content of options around analyst recommendations
}

Wang, Qingxia; Faff, Robert; Zhu, Min

Published in:

International Journal of Managerial Finance

DOI:

10.1108/IJMF-04-2021-0168

Licence:

Other

Link to output in Bond University research repository.

Recommended citation(APA):

Wang, Q., Faff, R., \& Zhu, M. (2022). Informational content of options around analyst recommendations. International Journal of Managerial Finance, 18(3), 445-465. https://doi.org/10.1108/IJMF-04-2021-0168

\footnotetext{
General rights

Copyright and moral rights for the publications made accessible in the public portal are retained by the authors and/or other copyright owners and it is a condition of accessing publications that users recognise and abide by the legal requirements associated with these rights.
}

For more information, or if you believe that this document breaches copyright, please contact the Bond University research repository coordinator. 


\title{
Informational content of options around analyst recommendations
}

\author{
Qingxia (Jenny) Wang * \\ Email: q.wang@business.uq.edu.au \\ Business School, The University of Queensland, Australia. \\ Robert Faff \\ Email: r.faff@business.uq.edu.au \\ Business School, The University of Queensland, Australia. \\ Email: rfaff@bond.edu.au \\ Business School, Bond University, Australia.

\section{Min Zhu} \\ Email: m.zhu@business.uq.edu.au \\ Business School, The University of Queensland, Australia.
}

\section{Acknowledgments:}

We have got material support from the University of Queensland for the research, but we are not supported by the external fund.

\section{Declarations of interest:}

None.

\section{* Corresponding author.}

We thank Alfred Yawson (Editor-in-Chief) and an anonymous referee for their helpful suggestions that grealy improved this paper. We also thank Kam Fong Chan, David Gallagher, Khoa Hoang, Maggie Liu, Casavecchia, Lorenzo, Suman Neupane-Joshi, Buhui Qiu, Eric Tan, Kelvin Tan, and seminar participants at Financial Market and Corporate Governance Conference 2019, Sydney, for their valuable comments and suggestions. We are also grateful for Kam Fong Chan's assistance on part of programming. 


\title{
Informational content of options around analyst recommendations
}

\begin{abstract}
We examine the informational content of options around unscheduled corporate news events. Specifically, we construct the model-free implied variance and decompose it into upside (good) and downside (bad) variances. We show that the pre-event good (bad) implied variance contains distinctive information on stock returns, i.e., good (bad) implied variance is positively (negatively) related to post-recommendation stock returns. This relation extends over several days after recommendation changes and is robust after controlling for well-known firm characteristics and higher-order (i.e., third and fourth) implied moments. The ordered probit model shows that the findings are more consistent with the analyst tipping hypothesis.
\end{abstract}

JEL classification: G12; G14; G24

Keywords: Good (bad) implied variance; Informed traders; Analyst recommendations; Analyst tipping 


\section{Introduction}

Prior studies provide evidence that the option market contains useful predictive information on stock returns (Easley et al., 1998; Pan and Poteshman, 2006; Xing et al., 2010; Conrad et al., 2013; Guo and Qiu, 2014; Wang and Yen, 2019). ${ }^{1}$ Studies also document a strong relation between option measures and stock returns during scheduled corporate events (Diavatopoulos et al., 2012; Atilgan, 2014; Lei et al., 2020) and unscheduled events (Hayunga and Lung, 2014; Chan et al., 2015; Lin and Lu, 2015). The present study adds to the literature and investigates the informational role of options in relation to stock returns following unscheduled corporate news events. Specifically, we investigate whether option implied volatility estimated prior to analyst recommendation changes contains information on subsequent stock returns around analyst recommendations. ${ }^{2}$

There are currently two main categories of option implied measures of information. The first category includes implied volatility (IV) spread presented in Cremers and Weinbaum (2010) and $I V$ skew proposed by Xing et al. (2010). The second category involves model-free implied volatility, skewness, and kurtosis (i.e., MFIV, MFIS, and MFIK) developed by Bakshi et al. (2003). In exploring information content of implied option measures around important firm events, researchers have extensively investigated $I V$ spread and $I V$ skew. For example, Atilgan (2014) and Lei et al. (2020) exam $I V$ spread around earnings announcements. Hayunga and Lung (2014) employ $I V$ spread and $I V$ skew to study the trading behavior of option markets around consensus revisions of financial analysts. Chan et al. (2015) and Lin and Lu (2015) investigate informational content of $I V$ spread and $I V$ skew prior to merger and acquisition

\footnotetext{
${ }^{1}$ Some studies also examine the predictability of option implied measures in forecasting volatilities, e.g., Byun and Kim (2013), Seo and Kim (2015), and Wang and Wang (2016).

2 Throughout this paper, we use the terms "implied volatility" and "implied variance" interchangeably.
} 
announcements and analyst news events, and Gharghori et al. (2017) use similar option implied measures for stock split announcements.

For the model-free implied measures, previous studies provide empirical evidence that model-free implied measures contain richer information because of a continuum of option strike prices (Vanden, 2008). Rehman and Vilkov (2012) and Conrad et al. (2013) show that MFIS is closely related to future stock returns. While, Rehman and Vilkov (2012) find a positive relation, Conrad et al. (2013) document a negative one. Regarding information content of model-free implied measures around firm events, only Diavatopoulos et al. (2012) investigate their predictability prior to earnings announcements. As such, more research is warranted to identify and distinguish the informational role of model-free implied measures and provide insights for investment and risk management. We aim to extend the studies in this area, especially to examine the characteristics of model-free implied measures around unscheduled events, e.g., analyst recommendation announcements.

Our sample consists of approximately 10,000 recommendation changes for 359 firms over a 20-year sample period from 1996 to 2015. We define a recommendation change if a given analyst upgrades or downgrades her prior recommendation. As Loh and Stulz (2011, p. p.595) state, “...analysts often write reports on days of firm-specific news, and recommendation changes on such days are more likely to be favorable [unfavorable] if the firm has positive [negative] news ..." At the same time, Conrad et al. (2013) and many others find that option implied moments are associated with subsequent stock returns. We exploit Loh and Stulz's (2011) argument, together with Conrad et al.'s (2013) findings, and hypothesize that a significant portion of the firm-specific news that informed analysts are often privy to, is impounded in options prior to recommendation changes. Therefore, it is plausible that the prerecommendation option market is strongly related to recommendation returns, even though the event (i.e., recommendation changes) is largely "unplanned". 
We employ the model-free implied variance (MFIV) of Bakshi, Kapadia and Madan (2003, henceforth BKM) and especially its two components - upside (good) and downside (bad) variance, i.e., $M F I V^{g}$ and $M F I V^{b}$, as our option implied measures. By construction, $M F I V^{g}$ is associated with the call option, and $M F I V^{b}$ is associated with the put option. In related studies, Feunou et al. (2018) and Kilic and Shaliastovich (2018) show that good and bad components of the variance risk premium, which are measured by option implied variance minus the expected realized variance, play different roles in relation to stock returns.

We estimate these option implied measures on the day preceding recommendation changes. We first separate our sample into downgrades and upgrades and observe a significantly negative and positive relation between $M F I V$ and post-event stock returns, respectively. ${ }^{3}$ However, the significant relation disappears when we examine the nondirectional recommendation changes (i.e., when we consider both upgrades and downgrades concurrently). Intuitively, $M F I V$ is composed of components that contain distinctive information on subsequent stock returns. In particular, we find that $M F I V^{g}$ and $M F I V^{b}$ are positively and negatively related to post-event stock returns, respectively.

In addition, prior studies have shown that higher-order (i.e., third and fourth) implied moments are strongly associated with stock returns during scheduled corporate events; see, for example, Diavatopoulos et al. (2012) on earnings announcements. In contrast, we show that the option implied variance (i.e., second moment) subsumes the informational role of the higher-order implied moments on stock returns upon unscheduled events in the form of analyst recommendation changes. ${ }^{4}$ We further find that the good and bad option variances $\left(M F I V^{g}\right.$ and $\left.M F I V^{b}\right)$ are strongly related to stock returns up to six days subsequent to recommendation changes.

\footnotetext{
${ }^{3}$ In this paper, in describing our results, the term "post-event" or "post-recommendation" includes the recommendation day and its following day(s).

${ }^{4}$ Similarly, Doran et al. (2007) provide weak evidence of return predictability afforded by higher-order implied volatility skews.
} 
Finally, we examine whether our findings are related to the prediction hypothesis or the analyst tipping hypothesis. The prediction hypothesis postulates that informed traders use available information on the firm (e.g., earnings) to infer the direction of the upcoming recommendation about the stock and guide their trading activities. Following Christophe et al. (2010) and Lin and Lu (2015), we partition observations into terciles by sorting on MFIV ${ }^{g}$ and $M F I V^{b}$. If informed traders analyze the firm's most recent quarterly earnings to extract information on the firm's performance, we expect to observe a more positive (negative) earnings surprise in the high $M F I V^{g}\left(M F I V^{b}\right)$ tercile. However, the results do not provide evidence supporting this pattern, indicating that our results are not consistent with the prediction hypothesis.

The analyst tipping hypothesis posits that informed traders acquire information from analyst tips on the upcoming recommendations. To test this hypothesis, we employ the ordered probit model. Given that extreme recommendation changes (that is, analysts downgrade (upgrade) stocks by 3 or 4 rating levels) are rare, we group these categories into the category 2 or +2 . The results show that the pre-event $M F I V^{g}$ and $M F I V^{b}$ are positively and negatively related to recommendation changes, respectively. Specifically, a unit standard deviation increase in $\mathrm{MFIV}^{g}\left(M F I V^{b}\right)$ is significantly related to a $2.8 \%(3.6 \%)$ increase (decrease) in the probability that the firm's next-day rating would be upgraded (downgraded) by two rating levels.

In relation to the informational role of options on unplanned corporate events, a number of studies, for example, Cao et al. (2005), Jin et al. (2012), Hayunga and Lung (2014), Chan et al. (2015), Lin and $\mathrm{Lu}$ (2015), and Cremers et al. (2020) have provided empirical evidence. In particular, Jin et al. (2012) find that option traders have useful information on stock returns prior to unscheduled news announcements (e.g., executive changes and litigations) and the option predictability is stronger post-events. Hayunga and Lung (2014) and Lin and Lu (2015) 
show that option traders are informed around upcoming analyst-related news. Cao et al. (2005) and Chan et al. (2015) demonstrate that the option market is informative in relation to stock returns following unanticipated news pertaining to mergers and acquisitions. ${ }^{5}$

Our study examines the informational role of options on analyst recommendation changes and contributes to the relevant literature in several key respects. First, our study supplements and enhances the set of studies that provides inconclusive evidence on the relation between the high-order implied moments and subsequent stock returns. For example, Rehman and Vilkov (2012) and Conrad et al. (2013) report opposite relations between model-free option implied skewness (MFIS) and future stock returns. Diavatopoulos et al. (2012) find that MFIS and MFIK have strong relations with post-earnings announcement stock returns. Similarly, Hayunga and Lung (2014) and Lin and Lu (2015) document a significant predictive role of $I V$ skew on future stock returns around analyst recommendation announcements. Notably, we do not find a significant effect of MFIS in predicting future stock returns when model-free implied volatility is partitioned into good and bad components $\left(M F I V^{g}\right.$ and $\left.M F I V^{b}\right)$, suggesting that the separation of option implied volatility could include the information involved in skewness. Moreover, the pre-recommendation $M F I V^{g}$ and $M F I V^{b}$ contain distinctive information and are associated differently with stock returns following recommendation changes.

Second, our work serves to further promote studies exploring the predictability of modelfree implied measures around firms' important events. To our best knowledge, apart from our study on analyst recommendations, only Diavatopoulos et al. (2012) investigate earnings announcement events using model-free implied measures. Empirical evidence documents some advantages in using model-free implied measures. For example, Jiang and Tian (2005) show that $M F I V\left(M F I V^{g}\right.$ and $\left.M F I V^{b}\right)$ subsumes all information in the Black-Scholes implied

\footnotetext{
${ }^{5}$ By contrast, Gharghori et al. (2017) provide weak evidence that the option market has predictive information on stock prices during unplanned stock split announcements.
} 
volatility. Vanden (2008) corroborates these findings by arguing that $M F I V\left(M F I V^{g}\right.$ and $\left.M F I V^{b}\right)$ is (are) more useful and informative than Black-Scholes implied volatility because the former's estimation depends on a continuum of option strike prices with rich information (see Section 2), while the latter relies on options with a narrower range of strike prices with limited information. Moreover, although we do not find significant predictability of higher-order model-free implied moments (i.e., MFIS and $M F I K$ ) on post-analyst recommendations, the informational content of model-free implied measures around other firms' events, such as mergers and acquisitions, and dividend announcements, is worth exploring in future work.

Finally, we also contribute to the literature on analyst recommendations. While our study is, in spirit, similar to Hayunga and Lung (2014), we use alternative measures of recommendation change that offer us a distinct empirical advantage. More specifically, Hayunga and Lung (2014) use consensus measures, contrasting our focus on individual analysts (Loh and Stulz, 2011). Our more nuanced approach is important because consensus discards a large amount of potentially valuable information via the aggregation process. Our recommendation change measure is also in line with Jegadeesh et al. (2004) and Jegadeesh and Kim (2010), which show that recommendation changes are more informative than recommendation levels in predicting stock returns.

The remainder of this paper proceeds as follows. Section 2 presents the econometric method used to estimate BKM's (2003) model-free implied variance. Section 3 describes the sample data and summary statistics. Section 4 discusses the empirical analyses and Section 5 concludes.

\section{Econometric method}

This study investigates whether and how stock options prior to analyst recommendation changes are related to subsequent stock returns. To address this issue, we use the model-free 
implied variance (MFIV) of BKM (2003) and its two components to measure the option information content.

Let $S(t)$ be the stock price at time $t$, and $R(t, \tau)=\ln S(t+\tau)-\ln S(t)$ is the $\log$ return over $\tau$-period. Bakshi and Madan (2000) show that the payoff of a security can be spanned using a set of options with continuum strike prices. BKM (2003) extend on this finding and show that the quadratic contract is priced as:

$$
V(t, \tau) \equiv E_{t}^{Q}\left\{e^{-r_{f} \tau} R(t, \tau)^{2}\right\}
$$

where $E_{t}^{Q}$ indicates the expectation under the risk-neutral measure, and $r_{f}$ is the risk-free rate. Following Rehman and Vilkov (2012) and Kilic and Shaliastovich (2018), we estimate Eq. (1) as:

$$
\begin{aligned}
V(t, \tau) & =\int_{S(t)}^{\infty} \frac{2\left(1-\ln \left[\frac{K}{S(t)}\right]\right)}{K^{2}} C(t, \tau ; K) d K \\
& +\int_{0}^{S(t)} \frac{2\left(1+\ln \left[\frac{S(t)}{K}\right]\right)}{K^{2}} P(t, \tau ; K) d K,
\end{aligned}
$$

where $V(t, \tau)=\tau$-period $M F I V$, and $C(t, \tau ; K)$ and $P(t, \tau ; K)$ denote the respective prices of call and put options written on the stock with strike price $K$ and maturity $\tau$.

Segal et al. (2015) decompose aggregate uncertainty into good and bad components and show that they have opposite effects on asset price. Kilic and Shaliastovich (2018) also document that the variance risk premium is driven separately by good and bad components. All these findings suggest that different components contain distinctive information on future stock returns. In a spirit similar to these studies, we examine how the asymmetric effect of option implied variance is associated with post-recommendation abnormal stock returns. In particular, we decompose $M F I V$ in Eq. (2) into upside (good) implied variance $\left(M F I V^{g}\right)$, which 
is associated with the call option, and downside (bad) implied variance $\left(M F I V^{b}\right)$, which is related to the put option:

$$
M F I V^{g}=\int_{S(t)}^{\infty} \frac{2\left(1-\ln \left[\frac{K}{S(t)}\right]\right)}{K^{2}} C(t, \tau ; K) d K,
$$

and

$$
M F I V^{b}=\int_{0}^{S(t)} \frac{2\left(1+\ln \left[\frac{S(t)}{K}\right]\right)}{K^{2}} P(t, \tau ; K) d K
$$

We follow Carr and $\mathrm{Wu}$ (2009) and interpolate 1,001 Black-Scholes option implied volatility on day $t$ using piecewise cubic spline interpolation. We assume that the volatility curve is flat for implied volatilities whose strike prices are not available in the OptionMetrics dataset. We use this fine grid of implied volatility dataset to estimate $C(t, \tau ; K)$ and $P(t, \tau ; K)$. With $C(t, \tau ; K)$ and $P(t, \tau ; K)$ on hand, we follow Dennis and Mayhew (2002) and approximate the integrals in Eq. (2) using a trapezoidal rule. This gives us the $\tau$-period $M F I V$. Following convention, we focus on $\tau=30$, which we obtain by linearly interpolating $M F I V$ s with the nearest $\tau$-expirations. Similarly, both $M F I V^{g}$ and $M F I V^{b}$ are estimated using the same procedure used to calculate the total $M F I V$.

\section{Data and descriptive statistics}

\subsection{Data}

We classify the sample data into three groups: stocks, options, and analyst recommendations. The availability of the option data dictates that our sample period covers January 2, 1996 to December 31, 2015.

For stocks, we limit ourselves to the constituents listed on the S\&P 500 index as of December 2015. This keeps the analyses (which also involve options) to a manageable level. 
We source the daily stock returns from the Center for Research in Security Prices (CRSP) database and counterpart accounting-related data such as firm size and book-to-market $(B M)$ ratio from the Compustat database.

For stock options, we extract the data from OptionMetrics and the risk-free rate from the Zero Coupon Yield Curve file of OptionMetrics. To ensure that the analyses involving MFIV yield statistically meaningful findings, we follow prior literature (see, e.g., Neumann and Skiadopoulos, 2013) and exclude options with missing implied volatility, zero open interest, and zero bid or ask price. We also discard inactively traded options with option delta above 0.99 and below 0.01 . We further omit puts with option moneyness $K / S$ greater than 1.2 and calls with $K / S$ less than 0.8 ; this eliminates deep-in-the-money options which are typically traded infrequently. Finally, we retain option data if there are at least two calls and two puts for a given date, and the midpoint of the best bid and offer prices is greater than 0.375 .

For analyst recommendations, we extract the data from the Institutional Brokers' Estimate System (I/B/E/S) analyst recommendation detail file. I/B/E/S ranks recommendations from 1 to 5. For ease of interpretation, we follow Howe et al. (2009) and Loh and Stulz (2011) and reverse the recommendation ratings so that the highest (lowest) rating represents the most (least) favourable recommendation. We require an analyst recommendation to have a CUSIP number and a recommendation date, and it must be issued by a qualified analyst with an analyst code (this allows us to track recommendations issued by the same analyst). The relevant stock must also have a matching option prior to recommendation changes.

We analyze changes, rather than levels, in analyst recommendations. Changes in the recommendation are more appropriate in the current context because our primary focus is to examine the extent to which the option market preceding analyst recommendations reflects incremental information that the analyst possesses, and this (incremental) information is embedded in changes in the recommendation. In addition, Jegadeesh et al. (2004) find that 
recommendation levels provide little incremental investment value relative to other investment signals, and Jegadeesh and Kim (2010) show that recommendation changes are more informative than levels in predicting stock returns.

To estimate the recommendation change, we follow Loh and Stulz (2011) and calculate the difference between current and prior ratings made by the same analyst. Since recommendation levels range from 1 (sell) to 5 (strong buy), recommendation changes, by construction, cover values between -4 and +4 . We omit zero recommendation changes (these account for nearly 3,000 recommendation reiterations and affirmations over the sample period) because zero changes suggest that the analysts possess no incremental new information. We also follow Barber et al. (2007) and remove outdated observations whose prior recommendation exceeds one year. To alleviate the confounding effect of other corporate announcements, we further exclude recommendation changes that occur within the $[-1,+1]$ days, earnings event window (Loh and Stulz, 2011). ${ }^{6}$ Finally, we follow Doran et al. (2010) and (i) remove conflicting recommendation changes made by multiple analysts on the same day, and (ii) treat identical recommendation changes made by multiple analysts on the same day as a single revision.

\subsection{Descriptive statistics}

After applying these filters, we have 9,951 recommendation changes, involving 359 stocks. Figure 1 plots the yearly number of stocks and analyst recommendations over the sample period. In general, the number of stocks increases almost monotonically from year 1996 to year 2011, which is probably because more stocks start option trading. Accordingly, the number of analyst recommendations increases in line with the number of stocks. After that, the

\footnotetext{
${ }^{6}$ We source the firm's quarterly earnings announcements from I/B/E/S. Altınkılıç and Hansen (2009) show that analyst recommendation changes exert an insignificant impact on stock returns once confounding corporate events are removed. Therefore, the removal of recommendation changes that coincide with earnings news allows us to obtain a "clean" and credible analysis.
} 
number of stocks and analyst recommendations decreases around 2012 with the internet bubble. This tendency is also observed in Berkman and Yang (2016).

\title{
$<$ Insert Figure 1 here $>$
}

Table 1 reports the transition matrix of recommendation changes across different analyst ratings. The total recommendation changes are split almost equally between downgrades and upgrades. Not surprisingly, analysts tend to upgrade from 'hold' (rating 3) to either 'buy' (rating 4) or 'strong buy' (rating 5), and a large portion also revise upward by one point from 'buy' to 'strong buy'. In terms of downgrades, analysts generally recommend a one-point revision from 'buy' to 'hold', and some revise from 'strong buy' to 'buy' or 'hold'. Loh and Stulz (2011) and Berkman and Yang (2016) also document a similar transition pattern.

\section{$<$ Insert Table 1 here $>$}

Table 2 supplements the descriptive statistics provided in Table 1 by reporting the yearly sample distribution of analyst recommendation changes, which range from -4 to +4 (excluding zero changes), while Figure 2 visualizes the analysis for total recommendation changes. Both Table 2 and Figure 2 show that recommendation changes are almost symmetrically distributed (4,847 downgrades and 5,104 upgrades). Further, nearly two-thirds of the recommendations change by one-point and one-third of the observations have a two-point revision. Analysts hardly make extreme revisions in their recommendations, with only $1.4 \%$ of recommendation changes classified as extreme upgrades $(+3 / 4)$ or extreme downgrades $(-3 / 4)$; see also Loh (2010).

\author{
$<$ Insert Table 2 here $>$ \\ $<$ Insert Figure 2 here $>$
}

\section{Empirical results}




\subsection{Event window study}

We first investigate the daily abnormal returns of stock $i\left(A R_{i}\right)$ over the $[-5,+5]$ event window surrounding the analyst recommendation change. Following Hayunga and Lung (2014) and many others, we define $A R_{i}$ as the stock daily return in excess of the risk-free rate minus the daily return predicted by the three-factor model of Fama and French (1993). ${ }^{7}$ Specifically, for each stock-trading day $t$, we estimate the following regression specification:

$$
r_{i, t}-r_{f, t}=\alpha_{i}+\beta_{i, M} M R P_{t}+\beta_{i, S} S M B_{t}+\beta_{i, H} H M L_{t}+\varepsilon_{i, t}
$$

where $r_{i, t}-r_{f, t}$ is the stock daily excess return and $M R P_{t}$ (market risk premium), $S M B_{t}$ (small minus big), and $H M L_{t}$ (high minus low) are the familiar market, size and value factors in Fama and French's (1993) three-factor model. We estimate Eq. (5) using a 150-day estimation window that covers day -155 to day -6 (i.e., six days prior to the recommendation change). We calculate abnormal returns $A R_{i, t}$ as:

$$
A R_{i, t}=\left(r_{i, t}-r_{f, t}\right)-\left[\hat{\beta}_{i, M} M R P_{t}+\hat{\beta}_{i, S} S M B_{t}+\hat{\beta}_{i, H} H M L_{t}\right]
$$

where $\hat{\beta}_{i, M}, \hat{\beta}_{i, S}$ and $\hat{\beta}_{i, H}$ are the estimated coefficients of Eq. (5).

Figure 3 plots the $A R$ of stocks for downgrades (Panel A) and upgrades (Panel B) over the $[-5,+5]$ event window. We observe that abnormal stock returns decrease (increase) considerably on the day of recommendation downwards (upwards).

\section{$<$ Insert Figure 3 here $>$}

\footnotetext{
${ }^{7}$ As a robustness check, we alternative estimate abnormal stock returns using the Fama and French (2015) fivefactor model and reach a similar qualitative finding. The results are not reported but are available from the authors upon request. We obtain the data on three- and five-factor returns from Kenneth French's data library (http://mba.tuck.dartmouth.edu/pages/faculty/ken.french/data_library.html).
} 


\subsection{Option implied measures and abnormal stock returns}

It is reasonable to assume that analysts are often privy to information about firm-specific news. We hypothesize that the option market impounds analysts' views and salient private information, and thus the pre-recommendation option market is strongly related to postrecommendation stock returns.

To test our proposition, we adopt the cross-sectional model specification of Savor (2012):

$$
\operatorname{CAR}_{i,(0,1)}=\alpha+\text { Boption }_{i, t-1}+\sum_{j=1}^{M} \gamma_{j} X_{i, j}+\varepsilon_{i, t}
$$

where $C A R_{i,(0,1)}$ is the cumulative Fama-French's adjusted abnormal return for stock $i$ over day $t=0$ and 1 , where $t=0$ is the analyst recommendation change date. Option ${ }_{i, t-1}$ refers to the 30 day maturity model-free implied variance $M F I V_{i, t-1}$, or its two components, $M F I V_{i, t-1}^{g}$ and $M F I V_{i, t-1}^{b}$, which are defined in Eqs. (2) - (4) and estimated a day prior to the analyst recommendation change. $X_{i, j}, j=1, \cdots, M$, represents a set of control variables, including firm size $\left(\log (\text { Size })_{i, t}\right)$, book-to-market ratio $\left(\log (B M)_{i, t}\right)$, momentum $\left(M O M_{i, t}\right)$, trading volume ratio $\left(\right.$ Volume $\left._{i, t-1}\right)$, and lagged abnormal return $\left(\operatorname{Lag} A R_{i, t-1}\right)$, which are firm-characteristic control variables commonly used in the cross-sectional regression. ${ }^{8}$

Table 3 reports the regression results between $M F I V$ and subsequent stock returns, with the parenthesized $t$-statistics estimated using clustered standard errors adjusted for firm and calendar day (Lin and Lu, 2015). We also impose year fixed-effects in the regression. Panels $\mathrm{A}$ and $\mathrm{B}$ report the results for downgrades and upgrades, respectively. Panel $\mathrm{C}$ reports the non-

\footnotetext{
${ }^{8}$ The $\log ($ Size $)$ control variable captures the firm size effect of Banz (1981) and is calculated as the log of market capitalization; $\log (B M)$ captures the value premium, whereby the book value is estimated by taking the book value per share multiplied by the total number of shares outstanding; and $M O M$ captures the momentum effect of Jegadeesh and Titman (1993) and is estimated using stock returns from day -150 to day -6 . Volume and lagged returns are also documented as well-known variables relating to the cross-sectional stock returns (Lehmann, 1990; Conrad et al., 1994). Volume is calculated as the ratio of daily trading volume to total shares outstanding.
} 
directional recommendation changes (i.e., when we consider both upgrades and downgrades concurrently).

\section{$<$ Insert Table 3 here $>$}

Table 3 Model (1), Eq. (7) without control variables, shows a significantly negative estimate on $M F I V$, i.e., $-1.73(t$-statistic $=-4.08)$ for downgrades and a significantly positive estimate on $M F I V$, i.e., $1.22(t$-statistic $=3.11)$ for upgrades. However, the estimated coefficient on MFIV shown in Panel $\mathrm{C}$ is insignificant. Our intuition is that MFIV should consist of different components that contain distinctive information associated with post-event stock returns. In the spirit of Segal et al. (2015) and Kilic and Shaliastovich (2018), we regress the two components of $M F I V$, i.e., $M F I V_{i, t-1}^{g}$ and $M F I V_{i, t-1}^{b}$ on post-recommendation stock returns for the non-directional recommendation changes. Table 4 reports the results. Taking Model (1) for example, we observe a significantly positive estimate on $M F I V_{i, t-1}^{g}$ and a significantly negative estimate on $M F I V_{i, t-1}^{b}$, which are $6.28(t$-statistic $=2.85)$ and $-2.97(t$ statistic $=-3.17)$, respectively. Therefore, we argue that the two components of $M F I V$, i.e., $M F I V^{g}$ and $M F I V^{b}$, contain distinctive information on post-recommendation stock returns. ${ }^{9}$ As such, we focus the analysis in the following tests on the non-directional recommendation changes.

\section{$<$ Insert Table 4 here $>$}

Model (2) in Table 4 reports the estimates of Eq. (7) after controlling for firm characteristics (size, value, momentum, volume and lagged return). The magnitudes and

\footnotetext{
${ }^{9}$ We also test $M F I V^{g}$ and $M F I V^{b}$ for downgrades and upgrades separately. The unreported results show that $M F I V^{g}$ and $M F I V^{b}$ are sensitive to firm size. That is, the estimates on $M F I V^{g}$ and $M F I V^{b}$ are statistically significant for large firms which have above-median market capitalization; the estimate on $M F I V^{g}\left(M F I V^{b}\right)$ is only positively (negatively) significant for upgrades (downgrades), but they do now show joint significance. These findings further suggest that $M F I V^{g}$ and $M F I V^{b}$ contain distinctive information on post-event stock returns. Details of this alternative analysis are available from the authors upon request.
} 
statistical significance of $M F I V_{i, t-1}^{g}$ and $M F I V_{i, t-1}^{b}$ factors hardly change with the addition of these control variables. ${ }^{10}$ To further corroborate our findings, we extend regression Eq. (7) by adding two higher-order implied moments as control variables: model-free implied skewness (MFIS) and model-free implied kurtosis $(M F I K)$, which take corresponding values on day $1 .{ }^{11}$ Conrad et al. (2013) find that both MFIS and MFIK relate strongly to subsequent stock returns. Diavatopoulos et al. (2012) also show that both higher-order implied moments contain useful predictive information on stock returns around scheduled earnings announcements.

Table 4 Model (3) reports the regression estimates. Notably, the coefficient estimates on $M F I V_{i, t-1}^{g}$ and $M F I V_{i, t-1}^{b}$ are still significantly positive and negative, respectively. At the same time, the regression loadings on MFIS and MFIK are insignificant. In summary, the findings suggest that it is the pre-recommendation option implied second moment instead of higherorder moments that contains information on post-event stock returns in our sample.

\subsection{Option implied measures and abnormal stock returns beyond the two-day window}

In this section, we investigate the relation between pre-recommendation $M F I V_{i, t-1}^{g}$ and

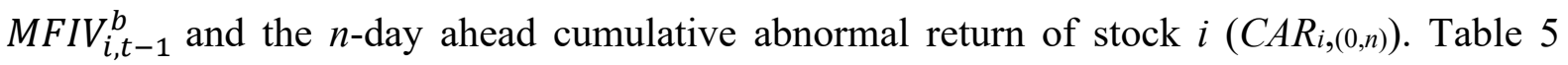
reports the results for $n=1, \ldots, 7$. We observe that the significance of the estimate on $M F I V_{i, t-1}^{g}$ continues to hold until $n=7$, but the significance of the estimate on $M F I V_{i, t-1}^{b}$ gradually decreases and disappears for $n=7$. These findings provide further evidence that that pre-event $M F I V_{i, t-1}^{g}$ and $M F I V_{i, t-1}^{b}$ contain distinctive information on post-event stock returns. Moreover, the relation between these implied variances and post-event stock returns is not just a one-day $(n=1)$ affair; rather, it extends to six days $(n=6)$ subsequent to recommendation changes.

\footnotetext{
${ }^{10}$ With the exception that the $\log (B M)$ factor has a marginally significant impact on stock returns, other control variables do not show significant effects.

${ }^{11}$ The appendix describes the calculations for MFIS and MFIK.
} 


\section{$<$ Insert Table 5 here $>$}

\subsection{The tipping hypothesis versus the prediction hypothesis}

In the previous sections, we find that $M F I V^{g}$ and $M F I V^{b}$ are strongly related to postrecommendation stock returns. This suggests that both $M F I V^{g}$ and $M F I V^{b}$ contain useful information about recommendation changes. In this section, we investigate whether informed traders benefit from tips from analysts before recommendations are released to the public (the tipping hypothesis) or they use their professional knowledge and skills to analyze the firm's fundamentals and extract useful information for their trading activities (the prediction hypothesis). ${ }^{12}$

\subsubsection{The prediction hypothesis}

Under the prediction hypothesis, while informed traders do not know exactly the recommendation announcement date, they might have some available information on the firm, such as unexpected earnings information. Following Christophe et al. (2010) and Lin and Lu (2015), we examine this hypothesis using the earnings surprise (SUR), which is calculated as the actual EPS less analysts' consensus forecast and scaled by the absolute value of the actual EPS of the most recent quarterly announcements preceding the recommendation changes. We sort the pre-recommendation $M F I V^{g}$ and $M F I V^{b}$ separately into terciles. If informed traders use relevant earnings information to predict the firm's performance or the recommendation direction, we expect to observe a significantly monotonic increase (decrease) of SUR with the increase of $M F I V^{g}\left(M F I V^{b}\right)$. Table 6 presents the results. Panel A and Panel B show the terciles sorted by $M F I V^{g}$ and $M F I V^{b}$, respectively. In particular, we find that the mean difference of

\footnotetext{
${ }^{12} \mathrm{Lin}$ and $\mathrm{Lu}$ (2015) state this hypothesis as the common information hypothesis, in which option traders and analysts have the same available information to draw the same conclusions.
} 
$S U R$ between high and low terciles is $0.005(t$-statistic $=0.25)$ for $M F I V^{g}$ and $-0.022(t$-statistic $=-0.77$ ) for $M F I V^{b}$. In summary, our findings are not consistent with the prediction hypothesis.

\section{$<$ Insert Table 6 here $>$}

\subsubsection{The tipping hypothesis}

To test the tipping hypothesis, we employ an ordered probit model to examine whether $M F I V^{g}$ and $M F I V^{b}$ play informational roles on upcoming recommendation changes. ${ }^{13}$ That is, we expect a significant estimate on $M F I V^{g}$ and $M F I V^{b}$. To this end, we define the analyst's recommendation changes for stock $i$ at date $t$ as follows: ${ }^{14}$

$$
\text { RecChange }_{i, t}= \begin{cases}-2 & \text { if recommendation change }=-2,-3 \text { or }-4 \\ -1 & \text { if recommendation change }=-1 \\ +1 & \text { if recommendation change }=+1 \\ +2 & \text { if recommendation change }=+2,+3 \text { or }+4\end{cases}
$$

Let $\operatorname{RecChang} e_{i, t}^{*}$ denote the unobservable continuous random variable and model it as:

$$
\operatorname{RecChang}_{i, t}^{*}=X_{i, t}^{\prime} \beta+\varepsilon_{i, t} \text {, }
$$

where $X_{i, t}$ is a vector of explanatory variables that contain the key variable of interest $\left(M_{F I V}^{g}\right.$ and $\left.M F I V_{i, t-1}^{b}\right)$ and control variables $\left(\log (\right.$ Size $) i, t, \log (B M)_{i, t}$, MOMi,t, Volume $i, t-1$, and $\operatorname{Lag} A R_{i, t-1}$ ), as defined earlier. $\beta$ is a vector of regression coefficients to be estimated. Note that the ordered probit model in Eq. (9) has a counterpart reported in Table 4. We assume that the error term $\varepsilon_{i, t}$ follows a standard normal distribution.

We relate the unobservable continuous variable $\left(\operatorname{RecChang}_{i, t}^{*}\right)$ to the observed discrete value $\left(\right.$ RecChange $\left._{i, t}\right)$ as follows:

\footnotetext{
${ }^{13}$ For ease of interpretation, we standardize $M F I V^{g}$ and $M F I V^{b}$ in the ordered probit model.

${ }^{14}$ Given that only $1.4 \%$ of the recommendation changes in our sample are classified as extreme upgrades or extreme downgrades (see Table 2), recommendation changes in the extreme categories $-3 / 4(+3 / 4)$ are included in category $-2(+2)$ for downgrades (upgrades).
} 


$$
\text { RecChange }_{i, t}= \begin{cases}-2 & \text { if RecChange } e_{i, t}^{*} \leq \alpha_{1} \\ -1 & \text { if } \alpha_{1}<\text { RecChange }_{i, t}^{*} \leq \alpha_{2} \\ +1 & \text { if } \alpha_{2}<{\text { RecChang } e_{i, t}^{*} \leq \alpha_{3}}_{+2} \text { if RecChange } \text { Ret, }_{i, t}^{*}>\alpha_{3}\end{cases}
$$

where $\alpha_{1}, \alpha_{2}$, and $\alpha_{3}$ are thresholds to reflect the partition of sample observations that fall within each recommendation change category and subject to the constraint $\alpha_{1}<\alpha_{2}<\alpha_{3}$.

Therefore, the probability of a set of explanatory variables that are associated with a recommendation change is presented as:

$$
\begin{aligned}
& \operatorname{Pr}\left(\text { RecChange }_{i, t}\right)= \begin{cases}\operatorname{Pr}\left(X_{i, t}^{\prime} \beta+\varepsilon_{i, t} \leq \alpha_{1}\right) & \text { if } \text { RecChang }_{i, t}=-2, \\
\operatorname{Pr}\left(\alpha_{1}<X_{i, t}^{\prime} \beta+\varepsilon_{i, t} \leq \alpha_{2}\right) & \text { if RecChang } e_{i, t}=-1, \\
\operatorname{Pr}\left(\alpha_{2}<X_{i, t}^{\prime} \beta+\varepsilon_{i, t} \leq \alpha_{3}\right) & \text { if RecChang } e_{i, t}=+1, \\
\operatorname{Pr}\left(X_{i, t}^{\prime} \beta+\varepsilon_{i, t}>\alpha_{3}\right) & \text { if RecChang } e_{i, t}=+2,\end{cases} \\
& = \begin{cases}\operatorname{Pr}\left(\varepsilon_{i, t} \leq \alpha_{1}-X_{i, t}^{\prime} \beta\right) & \text { if RecChange } \text { Re }_{i, t}=-2, \\
\operatorname{Pr}\left(\alpha_{1}-X_{i, t}^{\prime} \beta<\varepsilon_{i, t} \leq \alpha_{2}-X_{i, t}^{\prime} \beta\right) & \text { if RecChange } \operatorname{R}_{i, t}=-1, \\
\operatorname{Pr}\left(\alpha_{2}-X_{i, t}^{\prime} \beta<\varepsilon_{i, t} \leq \alpha_{3}-X_{i, t}^{\prime} \beta\right) & \text { if RecChange } \operatorname{Re}_{i, t}=+1, \\
\operatorname{Pr}\left(\varepsilon_{i, t}>\alpha_{3}-X_{i, t}^{\prime} \beta\right) & \text { if RecChange } \operatorname{R}_{i, t}=+2,\end{cases} \\
& = \begin{cases}\Phi\left(\alpha_{1}-X_{i, t}^{\prime} \beta\right) & \text { if RecChange } \text { Ret, }_{i, t}=-2, \\
\Phi\left(\alpha_{2}-X_{i, t}^{\prime} \beta\right)-\Phi\left(\alpha_{1}-X_{i, t}^{\prime} \beta\right) & \text { if RecChange } \text { Ret, }_{i, t}=-1, \\
\Phi\left(\alpha_{3}-X_{i, t}^{\prime} \beta\right)-\Phi\left(\alpha_{2}-X_{i, t}^{\prime} \beta\right) & \text { if RecChange } \text { Ret, }_{i, t}+1, \\
1-\Phi\left(\alpha_{3}-X_{i, t}^{\prime} \beta\right) & \text { if RecChange } \text { Ret, }_{i, t}+2,\end{cases}
\end{aligned}
$$

where $\Phi(\cdot)$ is the standard normal cumulative distribution function.

Table 7 presents the results of the ordered probit model for $M F I V_{i, t-1}^{g}$ and $M F I V_{i, t-1}^{b}$. For all three models, we observe a significantly positive estimate on $M F I V_{i, t-1}^{g}$ and negative estimate on $M F I V_{i, t-1}^{b}$.

\section{$<$ Insert Table 7 here $>$}

As $M F I V_{i, t-1}^{g}\left(M F I V_{i, t-1}^{b}\right)$ is positively (negatively) related to recommendation changes, Eq. (11) suggests that an increase in pre-event $M F I V^{g}\left(M F I V^{b}\right)$ increases the probability that analysts tend to upgrade (downgrade) the stock by at least one rating level. For simplicity, we 
take Model (1) to interpret our results. Specifically, a unit standard deviation increase in $M F I^{g}$ $\left(M F I V^{b}\right)$ increases the probability of upgrading (downgrading) the stock more than one rating level by $2.8 \%(3.6 \%)^{15}$. These findings demonstrate that the pre-event option implied good and bad variances are strongly associated with recommendation changes. Therefore, the results provide evidence for the analyst tipping hypothesis, consistent with the argument of Irvine et al. (2006) and Lin and $\mathrm{Lu}(2015){ }^{16}$

\subsection{Robustness tests}

In this section, we conduct two subsample tests to check the robustness of our results. First, we exclude the global financial crisis (GFC) period from our sample, i.e., from July 2007 to March 2009 (Loh and Stulz, 2018). During the GFC period, the financial markets were plagued with high uncertainty, so we test whether our results are driven by observations during this extreme period. Second, we test our sample after the Regulation Fair Disclosure (Reg FD) which is the rule approved by the Securities and Exchange Commission (SEC) and became effective on October $23,2000 .{ }^{17}$ The purpose of the regulation is to prevent the selective disclosure of material information by public companies to financial professionals. We remove the observations before the regulation to avoid contaminating our results. Table 8 reports the results for these two subsample tests. Overall, we find that our main results continue to hold.

\section{$<$ Insert Table 8 here $>$}

\footnotetext{
${ }^{15}$ For example, for Model (1) in Table 7, $\alpha_{3}=-0.97$, so the corresponding $1-\Phi(-0.97)=83.4 \%$. As such, a unit standard deviation increase in $M F I V^{g}$ leads to $\left.1-\Phi(-0.97-0.12)\right)=86.2 \%$. This implies an increase in the probability, which is calculated as $86.2 \%-83.4 \%=2.8 \%$, of upgrading the stock by two rating levels. Similarly, we can calculate the probability of downgrading the stock for a unit standard deviation increase in $M F I V^{b}$.

${ }^{16}$ Hobbs et al. (2012) further argue that investors are better off following the advice of security analysts who make their recommendation revisions more frequently.

${ }^{17}$ It would be interesting to study the difference in informed trading before and after the Reg FD in future research, as the Reg FD was released to reduce the financial market information asymmetry. In other words, all financial market participants should have access to the same public information.
} 


\section{Conclusions}

Analysts often have access to "valuable" firm-specific news prior to issuing recommendation changes. We posit that the option market impounds the "valuable" firmspecific news and thus, the pre-event option market is strongly related to post-recommendation stock returns even though recommendation changes are largely "unscheduled".

We provide evidence supporting the above contention. Specifically, we estimate individual firm option implied variance by employing BKM's (2003) model-free implied variance $(M F I V)$, and its two components, the good and bad implied variances (i.e., $M F I V^{g}$ and $\left.M F I V^{b}\right)$. We show that $M F I V^{g}$ and $M F I V^{b}$ are positively and negatively associated with postrecommendation stock returns, respectively. The findings are robust after controlling for firm characteristics and higher-order implied moments (MFIS and MFIK). In short, these results suggest that $M F I V^{g}$ and $M F I V^{b}$ contain distinctive information on subsequent stock returns.

We further investigate whether the relation between pre-event implied variances and post-event stock returns are more correlated to the prediction hypothesis or the tipping hypothesis. On the one hand, the results of sorting the earnings surprises into terciles based on $M F I V^{g}$ and $M F I V^{b}$ are inconsistent with the prediction hypothesis. On the other hand, our ordered probit test strongly supports the analyst tipping hypothesis and suggests that an increase in $M F I V^{g}\left(M F I V^{b}\right)$ increases the probability that analysts upgrade (downgrade) the stock. These findings provide implications for investors and risk managers in making investment decisions. In particular, the good and bad implied variances can be used as supplementary information to help predict stock price reactions, and in cases where the good or bad news is reinforced by other information, might allow a superior trading strategy to be implemented. 


\section{Appendix: Higher-order risk-neutral moments}

The prices of the cubic and quartic contracts are defined as $W(t, \tau) \equiv E_{t}\left\{e^{-r_{f} \tau} R(t, \tau)^{3}\right\}$ and $X(t, \tau) \equiv E_{t}\left\{e^{-r_{f} \tau} R(t, \tau)^{4}\right\}$, respectively. BKM (2003) present them as:

$$
\begin{aligned}
W(t, \tau)= & \int_{S(t)}^{\infty} \frac{6 \ln \left[\frac{K}{S(t)}\right]-3\left(\ln \left[\frac{K}{S(t)}\right]\right)^{2}}{K^{2}} C(t, \tau ; K) d K \\
& -\int_{0}^{S(t)} \frac{6 \ln \left[\frac{S(t)}{K}\right]+3\left(\ln \left[\frac{S(t)}{K}\right]\right)^{2}}{K^{2}} P(t, \tau ; K) d K,
\end{aligned}
$$

and

$$
\begin{aligned}
X(t, \tau)= & \int_{S(t)}^{\infty} \frac{12\left(\ln \left[\frac{K}{S(t)}\right]\right)^{2}-4\left(\ln \left[\frac{K}{S(t)}\right]\right)^{3}}{K^{2}} C(t, \tau ; K) d K \\
& +\int_{0}^{S(t)} \frac{12\left(\ln \left[\frac{S(t)}{K}\right]\right)^{2}+4\left(\ln \left[\frac{S(t)}{K}\right]\right)^{3}}{K^{2}} P(t, \tau ; K) d K .
\end{aligned}
$$

Accordingly, the model-free implied skewness (MFIS) and the model-free implied kurtosis $(M F I K)$ are given by:

$$
M F I S=\frac{e^{r_{f} \tau} W(t, \tau)-3 \mu(t, \tau) e^{r_{f} \tau} V(t, \tau)+2 \mu(t, \tau)^{3}}{\left[e^{r_{f} \tau} V(t, \tau)-\mu(t, \tau)^{2}\right]^{3 / 2}}
$$

and

$$
M F I K=\frac{e^{r_{f} \tau} X(t, \tau)-4 \mu(t, \tau) e^{r_{f} \tau} W(t, \tau)+6 e^{r_{f} \tau} \mu(t, \tau)^{2} V(t, \tau)-3 \mu(t, \tau)^{4}}{\left[e^{r_{f} \tau} V(t, \tau)-\mu(t, \tau)^{2}\right]^{2}},
$$

where $\mu(t, \tau)$ represents the risk-neutral expectation of the $\tau$-period $\log$ return, and is expressed as:

$$
\mu(t, \tau)=e^{r_{f} \tau}-1-\frac{e^{r_{f} \tau}}{2} V(t, \tau)-\frac{e^{r_{f} \tau}}{6} W(t, \tau)-\frac{e^{r_{f} \tau}}{24} X(t, \tau)
$$




\section{References}

Altınkılıç, O. and Hansen, R.S. (2009). On the information role of stock recommendation revisions. Journal of Accounting and Economics, 48(1), 17-36.

Atilgan, Y. (2014). Volatility spreads and earnings announcement returns. Journal of Banking and Finance, 38, 205-215.

Bakshi, G., Kapadia, N. and Madan, D. (2003). Stock return characteristics, skew laws, and the differential pricing of individual equity options. Review of Financial Studies, 16(1), 101-143.

Bakshi, G. and Madan, D. (2000). Spanning and derivative-security valuation. Journal of Financial Economics, 55(2), 205-238.

Banz, R.W. (1981). The relationship between return and market value of common stocks. Journal of Financial Economics, 9(1), 3-18.

Barber, B., Lehavy, R. and Trueman, B. (2007). Comparing the stock recommendation performance of investment banks and independent research firms. Journal of Financial Economics, 85(2), 490-517.

Berkman, H. and Yang, W. (2016). Analyst recommendations and international stock market returns. Working paper, Business School, University of Auckland.

Byun, S.J. and Kim, J.S. (2013). The information content of risk-neutral skewness for volatility forecasting. Journal of Empirical Finance, 23, 142-161.

Cao, C., Chen, Z. and Griffin, J.M. (2005). Informational content of option volume prior to takeovers. Journal of Business, 78(3), 1073-1109.

Carr, P. and Wu, L. (2009). Variance risk premiums. Review of Financial Studies, 22(3), 13111341.

Chan, K., Ge, L. and Lin, T.-C. (2015). Informational content of options trading on acquirer announcement return. Journal of Financial and Quantitative Analysis, 50(5), 10571082.

Christophe, S.E., Ferri, M.G. and Hsieh, J. (2010). Informed trading before analyst downgrades: Evidence from short sellers. Journal of Financial Economics, 95(1), 85-106.

Conrad, J., Dittmar, R.F. and Ghysels, E. (2013). Ex ante skewness and expected stock returns. Journal of Finance, 68(1), 85-124.

Conrad, J.S., Hameed, A. and Niden, C. (1994). Volume and autocovariances in short-horizon individual security returns. Journal of Finance, 49(4), 1305-1329.

Cremers, M., Fodor, A., Muravyev, D. and Weinbaum, D. (2020). How do informed option traders trade? Option trading activity, news releases, and stock return predictability. Available at: https://papers.ssrn.com/sol3/papers.cfm?abstract_id=2544344. 
Cremers, M. and Weinbaum, D. (2010). Deviations from put-call parity and stock return predictability. Journal of Financial and Quantitative Analysis, 45(2), 335-367.

Dennis, P. and Mayhew, S. (2002). Risk-neutral skewness: Evidence from stock options. Journal of Financial and Quantitative Analysis, 37(3), 471-493.

Diavatopoulos, D., Doran, J.S., Fodor, A. and Peterson, D.R. (2012). The information content of implied skewness and kurtosis changes prior to earnings announcements for stock and option returns. Journal of Banking and Finance, 36(3), 786-802.

Doran, J.S., Fodor, A. and Krieger, K. (2010). Option Market Efficiency and Analyst Recommendations. Journal of Business Finance and Accounting, 37(5-6), 560-590.

Doran, J.S., Peterson, D.R. and Tarrant, B.C. (2007). Is there information in the volatility skew? Journal of Futures Markets, 27(10), 921-959.

Easley, D., O'hara, M. and Srinivas, P.S. (1998). Option volume and stock prices: Evidence on where informed traders trade. Journal of Finance, 53(2), 431-465.

Fama, E.F. and French, K.R. (1993). Common risk factors in the returns on stocks and bonds. Journal of Financial Economics, 33(1), 3-56.

Fama, E.F. and French, K.R. (2015). A five-factor asset pricing model. Journal of Financial Economics, 116(1), 1-22.

Feunou, B., Jahan-Parvar, M.R. and Okou, C. (2018). Downside variance risk premium. Journal of Financial Econometrics, 16(3), 341-383.

Gharghori, P., Maberly, E.D. and Nguyen, A. (2017). Informed trading around stock split announcements: Evidence from the option market. Journal of Financial and Quantitative Analysis, 52(2), 705-735.

Guo, H. and Qiu, B. (2014). Options-implied variance and future stock returns. Journal of Banking and Finance, 44, 93-113.

Hayunga, D.K. and Lung, P.P. (2014). Trading in the options market around financial analysts' consensus revisions. Journal of Financial and Quantitative Analysis, 49(3), 725-747.

Hobbs, J., Kovacs, T. and Sharma, V. (2012). The investment value of the frequency of analyst recommendation changes for the ordinary investor. Journal of Empirical Finance, 19(1), 94-108.

Howe, J.S., Unlu, E. and Yan, X.S. (2009). The predictive content of aggregate analyst recommendations. Journal of Accounting Research, 47(3), 799-821.

Irvine, P., Lipson, M. and Puckett, A. (2006). Tipping. Review of Financial Studies, 20(3), 741768.

Jegadeesh, N., Kim, J., Krische, S.D. and Lee, C. (2004). Analyzing the analysts: When do recommendations add value? Journal of Finance, 59(3), 1083-1124. 
Jegadeesh, N. and Kim, W. (2010). Do analysts herd? An analysis of recommendations and market reactions. Review of Financial Studies, 23(2), 901-937.

Jegadeesh, N. and Titman, S. (1993). Returns to buying winners and selling losers: Implications for stock market efficiency. Journal of Finance, 48(1), 65-91.

Jiang, G.J. and Tian, Y.S. (2005). The model-free implied volatility and its information content. Review of Financial Studies, 18(4), 1305-1342.

Jin, W., Livnat, J. and Zhang, Y. (2012). Option Prices Leading Equity Prices: Do Option Traders Have an Information Advantage? Journal of Accounting Research, 50(2), 401432.

Kilic, M. and Shaliastovich, I. (2018). Good and bad variance premia and expected returns. Management Science, 1-23.

Lehmann, B.N. (1990). Fads, martingales, and market efficiency. Quarterly Journal of Economics, 105(1), 1-28.

Lei, Q., Wang, X.W. and Yan, Z. (2020). Volatility spread and stock market response to earnings announcements. Journal of Banking and Finance, 119, 1-16.

Lin, T.-C. and Lu, X. (2015). Why do options prices predict stock returns? Evidence from analyst tipping. Journal of Banking and Finance, 52, 17-28.

Loh, R.K. (2010). Investor inattention and the underreaction to stock recommendations. Financial Management, 39(3), 1223-1252.

Loh, R.K. and Stulz, R.M. (2011). When are analyst recommendation changes influential? Review of Financial Studies, 24(2), 593-627.

Loh, R.K. and Stulz, R.M. (2018). Is sell-side research more valuable in bad times? Journal of Finance, 73(3), 959-1013.

Neumann, M. and Skiadopoulos, G. (2013). Predictable dynamics in higher-order risk-neutral moments: Evidence from the S\&P 500 options. Journal of Financial and Quantitative Analysis, 48(3), 947-977.

Pan, J. and Poteshman, A.M. (2006). The information in option volume for future stock prices. Review of Financial Studies, 19(3), 871-908.

Rehman, Z. and Vilkov, G. (2012). Risk-neutral skewness: Return predictability and its sources. Available at: https://papers.ssrn.com/sol3/papers.cfm?abstract_id=1301648.

Savor, P.G. (2012). Stock returns after major price shocks: The impact of information. Journal of Financial Economics, 106(3), 635-659.

Segal, G., Shaliastovich, I. and Yaron, A. (2015). Good and bad uncertainty: Macroeconomic and financial market implications. Journal of Financial Economics, 117(2), 369-397. 
Seo, S.W. and Kim, J.S. (2015). The information content of option-implied information for volatility forecasting with investor sentiment. Journal of Banking and Finance, 50, 106120.

Vanden, J.M. (2008). Information quality and options. Review of Financial Studies, 21(6), 2635-2676.

Wang, Y.H. and Wang, Y.Y. (2016). The information content of intraday implied volatility for volatility forecasting. Journal of Forecasting, 35(2), 167-178.

Wang, Y.H. and Yen, K.C. (2019). The information content of the implied volatility term structure on future returns. European Financial Management, 25(2), 380-406.

Xing, Y., Zhang, X. and Zhao, R. (2010). What does the individual option volatility smirk tell us about future equity returns? Journal of Financial and Quantitative Analysis, 45(3), 641-662. 


\section{Table 1: The transition matrix of analyst recommendation changes}

This table reports the transition matrix of analyst recommendation changes, with the table row denoting prior recommendations and the table column denoting current recommendations. The table diagonal is left blank because we omit zero recommendation changes. ${ }^{18}$ The upper diagonal includes upgrades and the lower diagonal includes downgrades. The percentages in parentheses are the transition probabilities of prior recommendations to current recommendations. Section 3 describes the data filtering criteria. The sample period covers January 1996 to December 2015.

\begin{tabular}{lcccccc}
\hline & \multicolumn{5}{c}{ Current recommendation } & \\
\cline { 2 - 6 } $\begin{array}{l}\text { Prior } \\
\text { recommendation }\end{array}$ & $\begin{array}{c}1 \\
\text { (Sell) }\end{array}$ & $\begin{array}{c}2 \\
\text { (Underperform) }\end{array}$ & $\begin{array}{c}3 \\
\text { (Hold) }\end{array}$ & $\begin{array}{c}4 \\
\text { (Buy) }\end{array}$ & $\begin{array}{c}5 \\
\text { (Strong } \\
\text { buy) }\end{array}$ & Total \\
\hline 1 (Sell) & - & 38 & 259 & 15 & 21 & 333 \\
2 (Underperform) & 41 & - & 538 & 97 & 31 & 707 \\
3 (Hold) & 250 & 536 & - & 2163 & 1276 & 4225 \\
4 (Buy) & 15 & 87 & 1992 & - & 666 & 2760 \\
5 (Strong buy) & 29 & 27 & 1199 & 671 & - & 1926 \\
\hline $\begin{array}{l}\text { Total } \\
(\%)\end{array}$ & 335 & 688 & 3988 & 2946 & 1994 & 9951 \\
\hline
\end{tabular}

${ }^{18}$ The zero recommendation changes (on the table diagonal) for sell, underperform, hold, buy and strong buy are $26,155,1170,1190$, and 397 , respectively. 
Table 2: Annual distribution of analyst recommendation changes

This table reports the yearly distribution of recommendation changes which range from -4 to +4 and exclude zero changes. Section 3 describes the data filtering criteria. The sample period covers January 1996 to December 2015.

\begin{tabular}{|c|c|c|c|c|c|c|c|c|c|}
\hline \multicolumn{10}{|c|}{ Recommendation changes } \\
\hline & -4 & -3 & -2 & -1 & 1 & 2 & 3 & 4 & Total \\
\hline 1996 & 0 & 0 & 8 & 18 & 12 & 10 & 0 & 0 & 48 \\
\hline 1997 & 0 & 0 & 26 & 63 & 60 & 29 & 3 & 0 & 181 \\
\hline 1998 & 1 & 0 & 39 & 112 & 107 & 38 & 2 & 2 & 301 \\
\hline 1999 & 0 & 1 & 35 & 124 & 153 & 35 & 2 & 0 & 350 \\
\hline 2000 & 0 & 2 & 25 & 129 & 142 & 28 & 1 & 0 & 327 \\
\hline 2001 & 0 & 0 & 30 & 120 & 110 & 32 & 1 & 0 & 293 \\
\hline 2002 & 1 & 1 & 76 & 232 & 108 & 39 & 0 & 0 & 457 \\
\hline 2003 & 1 & 1 & 80 & 108 & 91 & 69 & 2 & 0 & 352 \\
\hline 2004 & 5 & 1 & 60 & 80 & 88 & 70 & 2 & 0 & 306 \\
\hline 2005 & 0 & 0 & 45 & 78 & 88 & 71 & 1 & 2 & 285 \\
\hline 2006 & 1 & 4 & 53 & 69 & 99 & 55 & 1 & 0 & 282 \\
\hline 2007 & 0 & 0 & 93 & 106 & 126 & 101 & 1 & 1 & 428 \\
\hline 2008 & 8 & 4 & 216 & 227 & 255 & 175 & 4 & 11 & 900 \\
\hline 2009 & 3 & 8 & 187 & 269 & 330 & 185 & 10 & 4 & 996 \\
\hline 2010 & 1 & 4 & 107 & 216 & 252 & 143 & 6 & 0 & 729 \\
\hline 2011 & 1 & 3 & 116 & 338 & 406 & 165 & 3 & 0 & 1032 \\
\hline 2012 & 3 & 2 & 111 & 322 & 299 & 124 & 3 & 0 & 864 \\
\hline 2013 & 2 & 2 & 82 & 217 & 266 & 108 & 2 & 1 & 680 \\
\hline 2014 & 2 & 5 & 73 & 205 & 190 & 60 & 2 & 0 & 537 \\
\hline 2015 & 0 & 4 & 74 & 207 & 223 & 95 & 0 & 0 & 603 \\
\hline $\begin{array}{c}\text { Total } \\
(\%)\end{array}$ & $\begin{array}{r}29 \\
(0.3)\end{array}$ & $\begin{array}{r}42 \\
(0.4)\end{array}$ & $\begin{array}{r}1536 \\
(15.4)\end{array}$ & $\begin{array}{r}3240 \\
(32.6)\end{array}$ & $\begin{array}{r}3405 \\
(34.2)\end{array}$ & $\begin{array}{r}1632 \\
(16.4)\end{array}$ & $\begin{array}{r}46 \\
(0.5)\end{array}$ & $\begin{array}{r}21 \\
(0.2)\end{array}$ & $\begin{array}{r}9951 \\
(100)\end{array}$ \\
\hline
\end{tabular}


Table 3: Cross-sectional regression results for the regression of $\mathrm{CAR}_{i,(0,1)}$ on MFIV

This table reports the cross-sectional regression of Eq. (7) and its modified versions after controlling for year fixed-effects. The parenthesized $t$-statistics are estimated using clustered standard errors adjusted for firm and calendar day. Panel A reports the results for 4,751 downgrades and Panel B reports the results for 5,002 upgrades. Panel $\mathrm{C}$ contains the results for the pooled sample of downgrades and upgrades with 9,753 observations. The sample covers the period January 1996 to December 2015. *, ** and *** denote significance levels at 10\%, 5\% and 1\%, respectively.

\begin{tabular}{|c|c|c|c|c|c|c|c|c|c|}
\hline \multirow[b]{2}{*}{ Model } & \multicolumn{3}{|c|}{ Panel A: Downgrades } & \multicolumn{3}{|c|}{ Panel B: Upgrades } & \multicolumn{3}{|c|}{ Panel C: Downgrades \& upgrades } \\
\hline & $(1)$ & $(2)$ & (3) & $(1)$ & $(2)$ & (3) & $(1)$ & $(2)$ & (3) \\
\hline \multirow[t]{2}{*}{ Intercept } & -0.31 & $-2.81 * *$ & $-2.88 * *$ & 1.26 & $4.27 * *$ & $4.25 * * *$ & 0.58 & 0.38 & 0.28 \\
\hline & $(-0.54)$ & $(-2.21)$ & $(-2.25)$ & $(2.06)$ & $(3.57)$ & $(3.54)$ & $(1.36)$ & $(0.39)$ & $(2.08)$ \\
\hline \multirow[t]{2}{*}{ MFIV } & $-1.73 * * *$ & $-1.66 * * *$ & $-1.63 * * *$ & $1.22 * * *$ & $0.92 * *$ & $-0.95 * *$ & -0.34 & -0.42 & -0.33 \\
\hline & $(-4.08)$ & $(-3.69)$ & $(-3.59)$ & $(3.11)$ & $(2.24)$ & $(-2.30)$ & $(-1.02)$ & $(-1.22)$ & $(-0.93)$ \\
\hline \multirow[t]{2}{*}{ MFIS } & & & 0.05 & & & 0.08 & & & $0.22 * * *$ \\
\hline & & & $(0.44)$ & & & $(1.05)$ & & & $(3.30)$ \\
\hline \multirow[t]{2}{*}{ MFIK } & & & 0.02 & & & 0.00 & & & $0.03 * *$ \\
\hline & & & $(0.90)$ & & & $(0.24)$ & & & $(2.00)$ \\
\hline \multirow[t]{2}{*}{$\log ($ Size $)$} & & $0.22 *$ & $0.22 *$ & & $-0.34 * * *$ & $-0.32 * * *$ & & -0.01 & 0.00 \\
\hline & & $(1.75)$ & $(1.75)$ & & $(-2.74)$ & $(-2.72)$ & & $(-0.04)$ & $(0.02)$ \\
\hline \multirow[t]{2}{*}{$\log (\mathrm{BM})$} & & $-0.28 * *$ & $-0.28 * *$ & & 0.03 & 0.02 & & $-0.16^{*}$ & $-0.17 * *$ \\
\hline & & $(-2.57)$ & $(-2.57)$ & & $(0.31)$ & $(0.26)$ & & $(-1.95)$ & $(-2.06)$ \\
\hline \multirow[t]{2}{*}{ MOM (scaled up by 1000) } & & -1.40 & -1.41 & & -1.95 & -1.96 & & -1.25 & -1.29 \\
\hline & & $(-0.90)$ & $(-0.92)$ & & $(-1.40)$ & $(-1.41)$ & & $(-1.08)$ & $(-1.11)$ \\
\hline \multirow[t]{2}{*}{ Volume } & & 4.12 & 4.02 & & 0.40 & 0.28 & & 2.33 & 1.99 \\
\hline & & $(1.28)$ & $(1.25)$ & & $(0.18)$ & $(0.13)$ & & $(0.97)$ & $(0.83)$ \\
\hline \multirow[t]{2}{*}{$\operatorname{LagAR}$} & & -0.02 & -0.02 & & $-0.10 * * *$ & $-0.09 * * *$ & & -0.02 & -0.02 \\
\hline & & $(-1.28)$ & $(-1.30)$ & & $(-5.58)$ & $(-5.54)$ & & $(-1.51)$ & $(-1.43)$ \\
\hline Adj. $R^{2}(\%)$ & 2.58 & 2.96 & 2.93 & 1.79 & 2.95 & 2.93 & 0.03 & 0.08 & 0.15 \\
\hline
\end{tabular}


Table 4: Cross-sectional regression results for the regression of $\mathrm{CAR}_{i,(0,1)}$ on $\mathrm{MFIV}^{\mathrm{g}}$ and MFIV

This table reports the cross-sectional regression of $\mathrm{CAR}_{i,(0,1)}$ on MFIV ${ }^{\mathrm{g}}$ and $\mathrm{MFIV}^{\mathrm{b}}$ after controlling for year fixed-effects. The parenthesized t-statistics are estimated using clustered standard errors adjusted for firm and calendar day. The results are for the pooled sample of downgrades and upgrades with 9,753 observations. The sample covers the period January 1996 to December $2015 .{ }^{*},{ }^{* *}$ and $* * *$ denote significance levels at $10 \%$, $5 \%$ and $1 \%$, respectively.

\begin{tabular}{lccc}
\hline Model & $(1)$ & $(2)$ & $(3)$ \\
\hline Intercept & 0.34 & 0.08 & 0.07 \\
& $(0.78)$ & $(0.08)$ & $(0.07)$ \\
MFIV $^{g}$ & $6.28^{* * *}$ & $6.07^{* * *}$ & $5.04^{* *}$ \\
& $(2.85)$ & $(2.70)$ & $(1.98)$ \\
MFIV & $-2.97^{* * *}$ & $-3.00^{* * *}$ & $-2.52^{* *}$ \\
& $(-3.17)$ & $(-3.14)$ & $(-2.27)$ \\
MFIS & & & 0.11 \\
& & & $(1.44)$ \\
MFIK & & & 0.02 \\
& & & $(1.42)$ \\
$\log ($ Size $)$ & & 0.01 & 0.01 \\
& & $(0.08)$ & $(0.09)$ \\
$\log (\mathrm{BM})$ & $-0.14 *$ & $-0.14 *$ \\
& & $(-1.69)$ & $(-1.78)$ \\
MOM (scaled up by 1000) & & -1.69 & -1.64 \\
& & $(-1.45)$ & $(-1.41)$ \\
Volume & & 1.73 & 1.66 \\
& & $(0.71)$ & $(0.68)$ \\
LagAR & & -0.02 & -0.02 \\
& & $(-1.40)$ & $(-1.39)$ \\
Adj. $R^{2}$ (\%) & & 0.22 & 0.23 \\
\hline
\end{tabular}


Table 5: Cross-sectional regression results for the regression of $\mathrm{CAR}_{i,(0, n)}$ on $\mathrm{MFIV}^{\mathrm{g}}$ and $\mathrm{MFIV}^{\mathrm{b}}$

This table reports the cross-sectional results of $\mathrm{CAR}_{\mathrm{i},(0, n)}$ for $n=1, \ldots, 7$, on MFIV ${ }^{\mathrm{g}}$ and MFIV after controlling for year fixed-effects. The parenthesized $t$ statistics are estimated using clustered standard errors adjusted for firm and calendar day. The results are for the pooled sample of downgrades and upgrades with 9,753 observations. The sample covers the period January 1996 to December $2015 . *{ }^{* *}$ and $* * *$ denote significance levels at $10 \%, 5 \%$ and $1 \%$, respectively.

\begin{tabular}{|c|c|c|c|c|c|c|c|}
\hline & $n=1$ & $n=2$ & $n=3$ & $n=4$ & $n=5$ & $n=6$ & $n=7$ \\
\hline \multirow[t]{2}{*}{ Intercept } & 0.07 & 2.09 & $4.07 * * *$ & $4.39 * * *$ & $4.99 * * *$ & $7.36^{* * *}$ & $7.59 * * *$ \\
\hline & $(0.07)$ & $(1.12)$ & $(3.35)$ & $(3.36)$ & $(3.41)$ & $(4.75)$ & (4.67) \\
\hline \multirow[t]{2}{*}{ MFIV $^{g}$} & $5.04 * *$ & $7.13 * *$ & $5.48^{*}$ & $7.88 * *$ & $11.03 * * *$ & $10.03 * * *$ & $8.14 * *$ \\
\hline & (1.98) & $(2.48)$ & $(1.79)$ & $(2.29)$ & (2.97) & $(2.61)$ & $(2.05)$ \\
\hline \multirow[t]{2}{*}{ MFIV $^{b}$} & $-2.52 * *$ & $-3.02 * * *$ & $-2.37 *$ & $-2.75^{*}$ & $-3.27 * *$ & $-2.94 *$ & -2.01 \\
\hline & $(-2.27)$ & $(-2.39)$ & $(-1.79)$ & $(-1.82)$ & $(-2.01)$ & $(-1.74)$ & $(-1.19)$ \\
\hline \multirow[t]{2}{*}{ MFIS } & 0.11 & 0.05 & 0.06 & 0.12 & 0.12 & 0.16 & $0.26^{* *}$ \\
\hline & (1.44) & $(0.52)$ & $(0.60)$ & $(1.21)$ & (1.14) & (1.38) & $(2.21)$ \\
\hline \multirow[t]{2}{*}{ MFIK } & 0.02 & 0.02 & 0.02 & 0.02 & 0.01 & 0.01 & 0.01 \\
\hline & $(1.42)$ & (1.15) & $(1.06)$ & (1.14) & $(0.84)$ & $(0.42)$ & $(0.66)$ \\
\hline \multirow[t]{2}{*}{$\log ($ Size $)$} & 0.01 & $-0.20 *$ & $-0.39 * * *$ & $-0.41 * * *$ & $-0.49 * * *$ & $-0.76 * * *$ & $-0.74 * * *$ \\
\hline & $(0.09)$ & $(-1.76)$ & $(-3.14)$ & $(-3.09)$ & $(-3.33)$ & $(-5.00)$ & (4.64) \\
\hline \multirow[t]{2}{*}{$\log (\mathrm{BM})$} & $-0.14^{*}$ & -0.06 & -0.14 & -0.16 & $-0.24 *$ & $-0.32 * *$ & $-0.32 * *$ \\
\hline & $(-1.78)$ & $(-0.57)$ & $(-1.29)$ & $(-1.42)$ & $(-1.94)$ & $(-2.49)$ & $(-2.39)$ \\
\hline \multirow[t]{2}{*}{ MOM (scaled up by 1000) } & -1.64 & 0.41 & -0.77 & -1.27 & -1.09 & -1.67 & -2.18 \\
\hline & $(-1.41)$ & $(0.31)$ & $(-0.55)$ & $(-0.81)$ & $(-0.64)$ & $(-0.94)$ & $(-1.21)$ \\
\hline \multirow[t]{2}{*}{ Volume } & 1.66 & -0.62 & 0.97 & 0.76 & -0.24 & 0.55 & -2.03 \\
\hline & $(0.68)$ & $(-0.24)$ & $(0.34)$ & $(0.26)$ & $(-0.08)$ & $(0.19)$ & $(-0.60)$ \\
\hline \multirow[t]{2}{*}{ LagAR } & -0.02 & -0.02 & -0.02 & -0.03 & -0.02 & -0.03 & $-0.05 * *$ \\
\hline & $(-1.39)$ & $(-1.43)$ & $(-1.21)$ & $(-1.44)$ & $(-1.06)$ & $(-1.61)$ & $(-2.14)$ \\
\hline Adj. $R^{2}(\%)$ & 0.23 & 0.19 & 0.17 & 0.26 & 0.41 & 0.64 & 0.61 \\
\hline
\end{tabular}




\section{Table 6: MFIV' and MFIV ${ }^{b}$ and earnings surprises}

This table reports the mean of earnings surprises for subsamples categorized by MFIV ${ }^{g}$ and MFIV ${ }^{b}$, shown in Panel A and Panel B, respectively. The earnings surprise (SUR) is calculated as the actual EPS minus the median value of the estimated EPS, and normalized by the absolute value of the actual EPS, which are from the most recent quarterly earnings announcements preceding analyst recommendation changes. The $t$ statistics are reported in parentheses. Obs. represents the number of recommendation changes in each tercile. High-Low reports the mean difference of SUR between high and low MFIV ${ }^{\mathrm{g}}\left(\mathrm{MFIV}^{\mathrm{b}}\right)$ subsamples.

\begin{tabular}{ccccc}
\hline & \multicolumn{3}{c}{ Terciles sorted by implied measures } & \\
\cline { 2 - 3 } & Low & Medium & High & High-Low \\
\hline Panel A: MFIV & & & & \\
Earnings surprise (SUR) & 0.030 & 0.017 & 0.035 & 0.005 \\
$\quad \begin{array}{c}t \text {-statistic } \\
\text { Obs. }\end{array}$ & $(4.51)$ & $(0.58)$ & $(1.99)$ & $(0.25)$ \\
Panel B: MFIV & 2995 & 2995 & 2995 & \\
Earnings surprise (SUR) & & & & \\
$\quad t$-statistic & 0.047 & 0.010 & 0.025 & -0.022 \\
Obs. & $(2.43)$ & $(0.51)$ & $(1.22)$ & $(-0.77)$ \\
\hline
\end{tabular}




\section{Table 7: Cross-sectional regression results of recommendation changes on $\mathrm{MFIV}^{\mathrm{g}}$ and}

MFIV ${ }^{b}$

This table reports the ordered probit estimates of Eq. (9) in relation to analyst recommendation changes. The results are for the pooled sample of downgrades and upgrades with 9,753 observations. The sample covers the period January 1996 to December 2015. The numbers in parentheses are $z$-statistics. *, ** and *** denote significance levels at $10 \%, 5 \%$ and $1 \%$, respectively.

\begin{tabular}{lccc}
\hline & Model (1) & Model (2) & Model (3) \\
\hline$\alpha_{1}$ & -1.01 & -0.99 & -0.99 \\
$\alpha_{2}$ & -0.03 & -0.00 & -0.00 \\
$\alpha_{3}$ & -0.97 & 1.00 & -1.00 \\
MFIVg & $0.12^{* * *}$ & $0.12^{* * *}$ & $0.09^{* * *}$ \\
& $(4.66)$ & $(4.57)$ & $(2.83)$ \\
MFIV & $-0.14^{* * *}$ & $-0.15^{* * *}$ & $-0.11^{* * *}$ \\
& $(-5.56)$ & $(-5.50)$ & $(-3.50)$ \\
MFIS & & & $0.07^{* * *}$ \\
& & & $(2.67)$ \\
MFIK & & & $0.01^{* *}$ \\
& & & $(2.26)$ \\
$\log ($ Size) (scaled up by 1000) & & 5.48 & 3.77 \\
& & $0.51)$ & $(0.35)$ \\
$\log (\mathrm{BM})$ & & $0.03^{*}$ & 0.02 \\
& & $(1.88)$ & $(1.66)$ \\
MOM (scaled up by 1000) & & 0.32 & 0.36 \\
& & $(1.11)$ & $(1.25)$ \\
Volume & & 0.19 & 0.11 \\
& & $(0.36)$ & $(0.20)$ \\
LagAR & & $0.02^{* * *}$ & $0.02^{* * *}$ \\
Pseudo $R^{2}$ (\%) & & $(4.40)$ & $(4.41)$ \\
\hline
\end{tabular}




\section{Table 8: Robustness tests for two subsamples}

This table reports the cross-sectional regression of $\mathrm{CAR}_{i,(0,1)}$ on $\mathrm{MFIV}^{\mathrm{g}}$ and $\mathrm{MFIV}^{\mathrm{b}}$ for two subsamples. We control for year fixed-effects. The parenthesized $t$-statistics are estimated using clustered standard errors adjusted for firm and calendar day. The full sample covers the period January 1996 to December 2015. Panel A shows the results for the subsample, in which the global financial crisis (GFC) period from July 2007 to March 2009 is excluded. The results are for the pooled sample of downgrades and upgrades with 8,402 observations. Panel B reports the results for the subsample after the Reg FD which was effective on October 23,2000 . The results are for the pooled sample of downgrades and upgrades with 8,667 observations. *, ** and $* * *$ denote significance levels at $10 \%, 5 \%$ and $1 \%$, respectively.

\begin{tabular}{|c|c|c|c|c|c|c|}
\hline \multirow[b]{2}{*}{ Model } & \multicolumn{3}{|c|}{ Panel A: Exclude GFC period } & \multicolumn{3}{|c|}{ Panel B: Afte Reg FD period } \\
\hline & (1) & (2) & (3) & (1) & (2) & (3) \\
\hline \multirow[t]{2}{*}{ Intercept } & 0.21 & -0.51 & -0.52 & $-1.57 * *$ & $-2.64^{*}$ & $-2.66^{*}$ \\
\hline & $(0.49)$ & $(-0.49)$ & $(-0.50)$ & $(-2.26)$ & $(-1.93)$ & $(-1.95)$ \\
\hline \multirow{2}{*}{ MFIV $^{g}$} & $8.76^{* * *}$ & $8.97 * * *$ & $8.79 * * *$ & $6.51 * * *$ & $6.27 * * *$ & $5.05^{*}$ \\
\hline & $(3.51)$ & $(3.54)$ & $(3.01)$ & $(2.84)$ & $(2.69)$ & $(1.91)$ \\
\hline \multirow[t]{2}{*}{ MFIV $^{b}$} & $-3.90 * * *$ & $-4.08 * * *$ & $-3.99 * * *$ & $-2.93 * * *$ & $-2.88 * * *$ & $-2.33 * *$ \\
\hline & $(-3.42)$ & $(-3.27)$ & $(-2.97)$ & $(-3.08)$ & $(-2.96)$ & $(-2.06)$ \\
\hline \multirow[t]{2}{*}{ MFIS } & & & 0.02 & & & 0.13 \\
\hline & & & $(0.22)$ & & & $(1.61)$ \\
\hline \multirow[t]{2}{*}{ MFIK } & & & 0.01 & & & 0.02 \\
\hline & & & $(0.56)$ & & & $(1.66)$ \\
\hline \multirow[t]{2}{*}{$\log ($ Size $)$} & & 0.06 & 0.06 & & 0.09 & 0.09 \\
\hline & & $(0.59)$ & $(0.59)$ & & $(0.76)$ & $(0.77)$ \\
\hline \multirow[t]{2}{*}{$\log (\mathrm{BM})$} & & $-0.14 *$ & $-0.14 *$ & & $-0.11 *$ & $-0.12 *$ \\
\hline & & $(-1.74)$ & $(-1.74)$ & & $(-1.19)$ & $(-1.26)$ \\
\hline \multirow[t]{2}{*}{ MOM (scaled up by 1000) } & & $-3.32 * * *$ & $-3.32 * * *$ & & -1.55 & -1.48 \\
\hline & & $(-2.74)$ & $(-2.74)$ & & $(-1.15)$ & $(-1.10)$ \\
\hline \multirow[t]{2}{*}{ Volume } & & 1.52 & 1.51 & & 1.84 & 1.78 \\
\hline & & $(0.59)$ & $(0.59)$ & & $(0.70)$ & $(0.68)$ \\
\hline \multirow[t]{2}{*}{ LagAR } & & -0.01 & -0.01 & & -0.02 & -0.02 \\
\hline & & $(-0.87)$ & $(-0.87)$ & & $(-1.09)$ & $(-1.09)$ \\
\hline Adj. $R^{2}(\%)$ & 0.23 & 0.34 & 0.32 & 0.35 & 0.38 & 0.39 \\
\hline
\end{tabular}




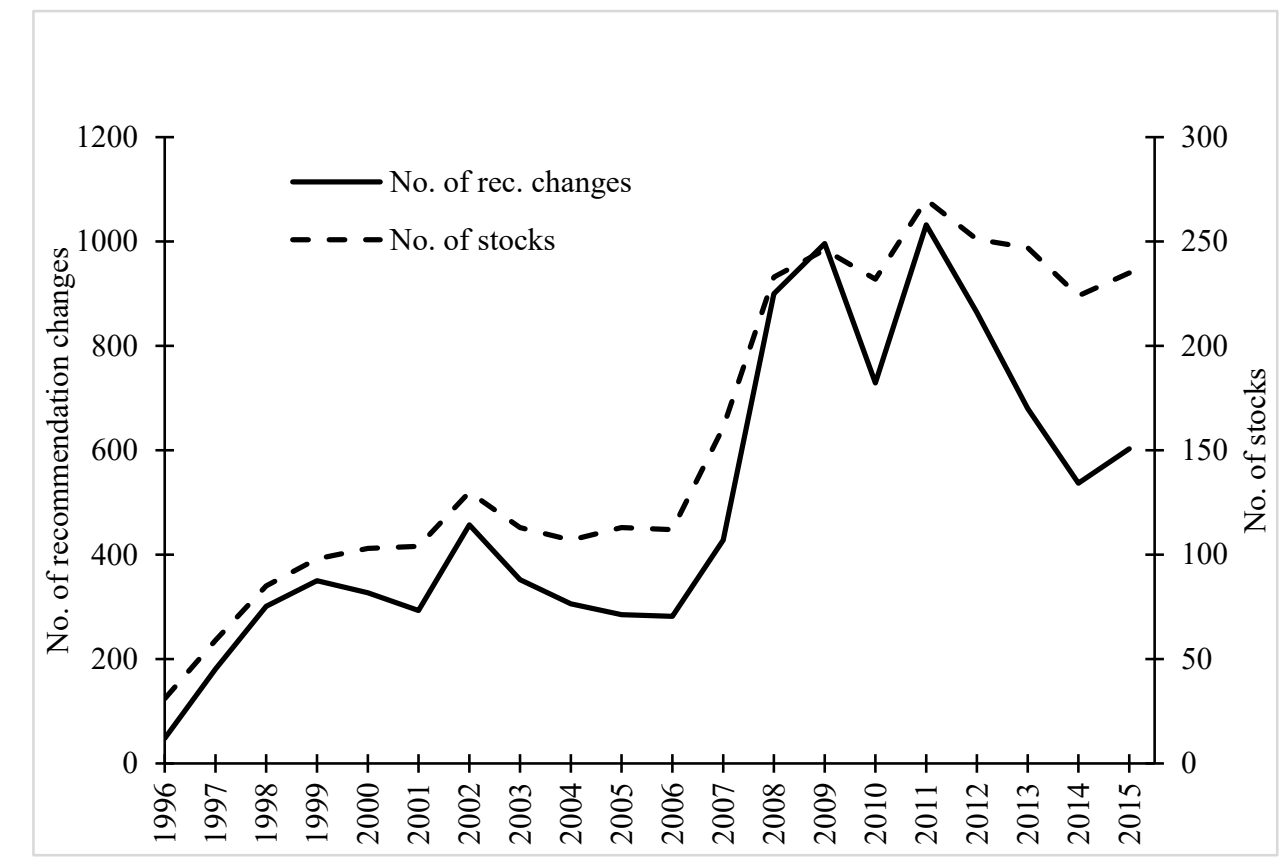

Figure 1: Numbers of stocks and recommendation changes over the sample period This figure shows the numbers of stocks and recommendation changes over the sample period. Section 3 describes the data filtering criteria. The sample period covers January 1996 to December 2015. 


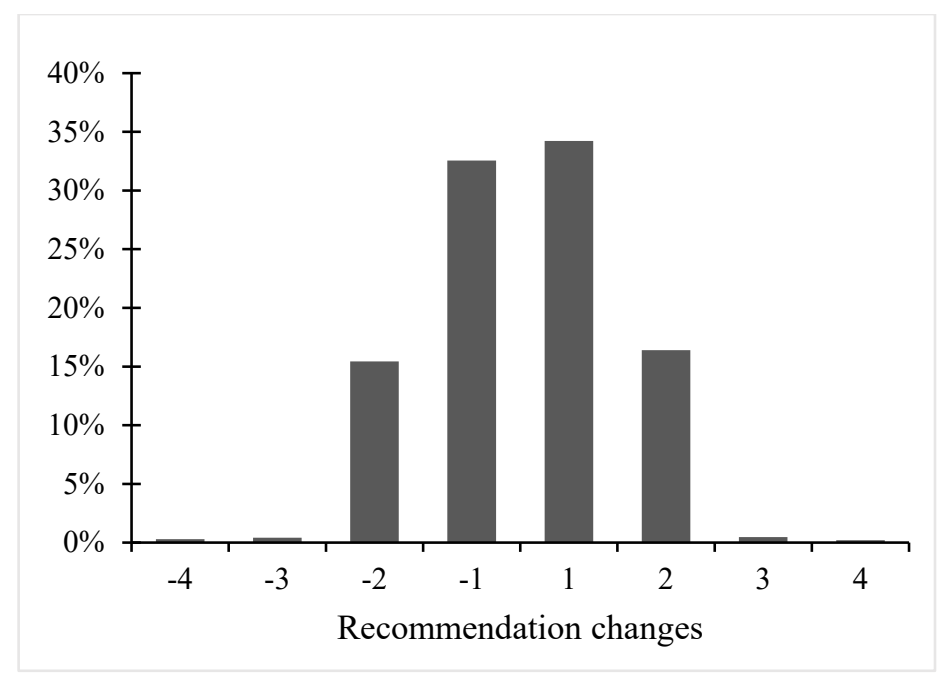

Figure 2: Percentage distribution of analyst recommendation changes

This figure shows the percentage distribution of recommendation changes which range from -4 to +4 and exclude zero changes. Section 3 describes the data filtering criteria. The sample period covers January 1996 to December 2015. 


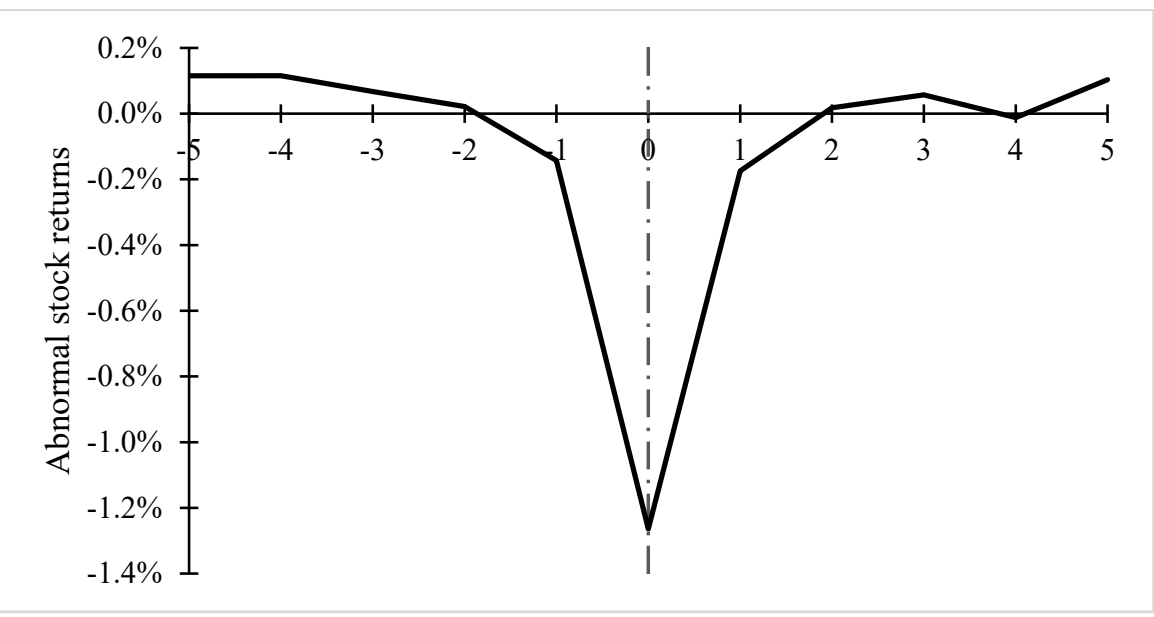

Panel A: Downgrades

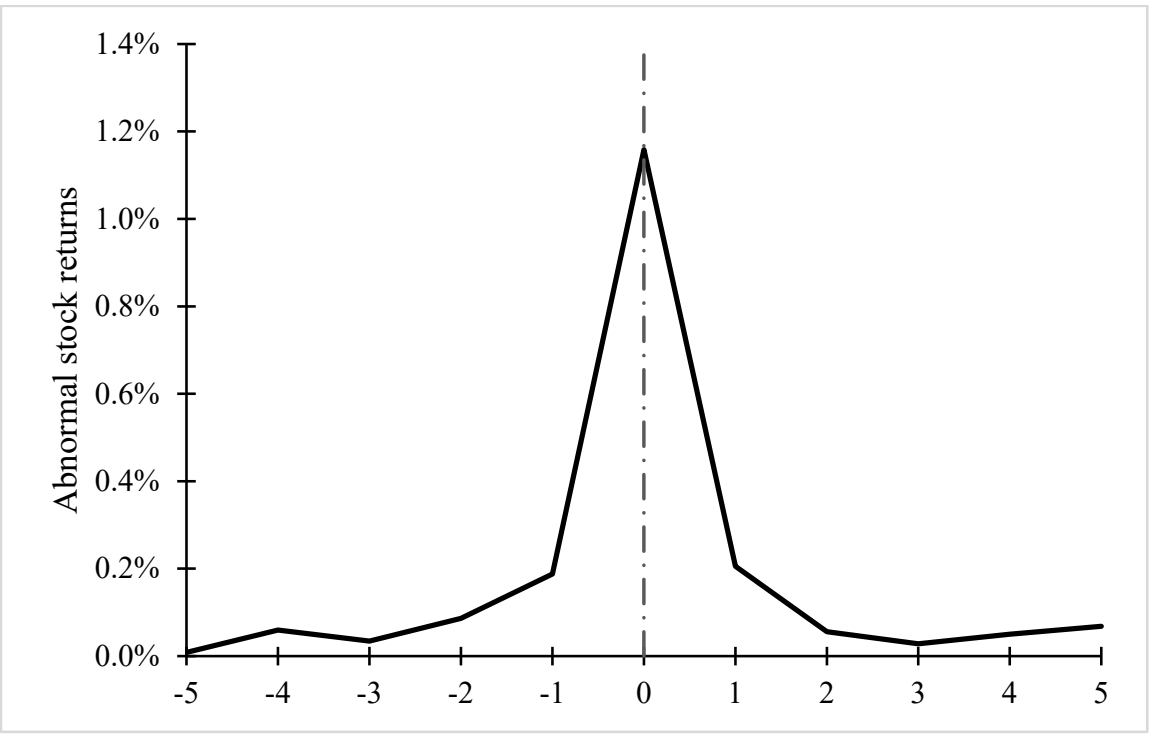

Panel B: Upgrades

Figure 3: Abnormal stock returns over the event window

This figure plots the abnormal stock returns over the $[-5,+5]$ event window surrounding analyst recommendation changes. Panel A shows the plot for downgrades and Panel B displays the plot for upgrades. The sample period covers January 1996 to December 2015. 